\title{
Actualization of Ethnic Identity in the Digital Age
}

\author{
Vladimir A. Inozemtsev ${ }^{1, *}$ Inal B. Sanakoev ${ }^{2, a}$ Nonna L. Bagramyants $^{1, b}$ \\ ${ }^{1}$ National Research University, Bauman Moscow State Technical University (BMSTU, 5 /1, 2d Baumanskaya \\ str., Moscow, Russia \\ ${ }^{2}$ South Ossetian State University after A. A. Tibilov, 8, Putina str., Tskhinval, Republic of South Ossetia \\ ${ }^{a}$ Email: inal59@mail.ru \\ ${ }^{b}$ Email: nonnalev@yandex.ru \\ *Corresponding author. Email: inozem_63@mail.ru
}

\begin{abstract}
The article examines various interpretations of the term "identity", including social identity and ethnic identity. It substantiates the content of the concept "identity" as a subject of research in sociology (and ethnosociology as its part), and psychology, including social psychology, its various areas, and psychoanalysis. The work considers approaches to the analysis of social and ethnic identity proposed by a number of foreign and Russian researchers. The article analyzes various types and levels, the structure and functions of ethnic identity. Based on the analysis of the processes of ethnic revival, the reasons for the actualization of ethnic identity in a digital society are revealed.
\end{abstract}

Keywords: Social identity, Ethnic identity, Identification, Digital society, Ethnic revival.

\section{INTRODUCTION}

One of the most important concepts related to ethnic issues in a digital society is the concept of ethnic identity. The emergence and development of this concept in ethnological research is associated with the spread of the term "identity", which in the 1960 s - 1970s gradually went beyond the psychological sciences. It should be noted that in scientific use, the concept of identity has quite a few different interpretations. The most common among them are "social identity" and "ethnic identity".

\section{SOCIAL IDENTITY}

Let us first consider some of the approaches to the study of social identity. Social identity is becoming a subject of research in sociology (and ethnosociology as its part), and psychology, including social psychology and psychoanalysis. In sociology, one of the most common definitions of the concept of social identity is proposed by A.

*Fund: The study was carried out with the financial support of the Russian Foundation for Basic Research (RFBR) in the framework of the scientific research project («Ethnosocial identity at the intersection of cultures in the changing social reality in the post-Soviet space»). Project № 21-511-07002.
Touraine, according to which social identity is the conscious self-determination of a social subject in the process of emotional self-identification of an individual, social group with another person, group or model, interiorization of occupied social statuses and the development of significant social roles [1].

Ethnosociology emphasizes an approach to the analysis of identity as a systemic category of social order. In the system of social relations, social identity appears as a positive definition of the subject of social action in its interaction with such institutions of society as the state, religion, family, profession, upbringing, family, etc. Thus, in these concepts, social identity appears in two aspects: in the first aspect, social identity is the typification of an individual as an object of social interaction, the so-called objectified identity. In the second aspect, social identity is subjective identity as an awareness of social categorization as a subject of social relations themselves.

Along with ethnological and sociological theories, the problem of social identity is being actively studied in various areas of social psychology, where it has been the subject of research since the late 1950s. One of the earliest and at the same time the most interesting approaches to the analysis of the concept of identity 
in social psychology is proposed by E. Erickson. He points out that the concept of "identity" simultaneously includes self-identity, internal awareness of similarity and the constant difference of any essential characteristic with others [2]. E. Erickson understands identity as both a subjective feeling and an objectively observed quality of personal sameness and continuity, coupled with a belief in the sameness and continuity of the image of the world shared with others.

Identity, according to E. Erickson, appears as a synthesis of the individual's awareness of his uniqueness, the characteristics of his personal being and, at the same time, the awareness of his belonging to a certain cultural and social community. Awareness of one's belonging to an ethnic group is for an individual the awareness of oneself, on the one hand, as a subject of intragroup interaction, which means the awareness and obligation of certain duties and rights, embodied through sociocultural roles. On the other hand, identity means the perception of oneself as a subject of intergroup and internal collective relations, and the awareness of oneself as an organic part of the community gives the individual a sense of confidence.

The concept of social identity itself was developed in the 1970s within the framework of social psychology, however, interest in the awareness of identity arose earlier in the psychological sciences and has its roots in psychoanalysis. In the works of the founder of psychoanalytic theory Z. Freud "Interpretation of Dreams" and "Group Psychology and Ego Analysis" the term "identification" is used. In "Interpretation of Dreams" Z. Freud uses this term first time, with the help of it he designates the early manifestations of the unconscious connection of a newborn child with other people (mainly parents), these manifestations having an emotional character. In the work "Group Psychology and Ego Analysis" the founder of psychoanalysis understands identification as the mechanism of interaction between a person and a social group.

If in the psychoanalytic tradition, identification has a personal status, in the socio-psychological literature through identification they denote emotional merging with the object, imitation, imitative behavior. In modern works on social psychology, the concepts of identity and identification are separated. So, when using the term "identity", the emphasis is on a certain state as the end result of self-identification. The identification is a set of processes and mechanisms that lead to this state [3].

One of the first substantiations of the content of the concept of "identity" in social psychology is undertaken in the works of W. James. Although W. James does not yet use the term "identity", but uses the concept of "character", it is he who first describes what is now called identity. As part of the study of the formation of personality, W. James singles out two aspects of the process of selfidentification, the individual's awareness of his "I", the definition of the boundaries of self-identity and his own place in reality. The first aspect, according to W. James, individual (I), characterizes personal self-identity, the second - collective (Me), characterizing the diversity of the individual's social I. Both of these aspects in unity reflect the sides of one holistic formation (self).

In the mainstream of the further development of the concepts of identity, one should refer to the works of E. Fromm, and above all to such work as "Escape from Freedom", in which not only the concept of identity is investigated, but also the motives of formation and types of identity are highlighted. The content of identity is laid down in the process of development and characterizes the involvement, belonging of a person to a certain social structure, awareness of his position and social status, for the individual it embodies the unity of the individual and social, the individual and the special. The emergence and formation of identity is conditioned by the necessity to meet the need for social belonging, the chance to occupy a certain social niche, it will protect from doubts and feelings of loneliness [4].

According to E. Fromm, an individual needs an awareness of belonging, co-belonging, and this need dictates to him the search for his social groups, be it professional associations, political parties and movements, church and charitable organizations, elements of subculture, etc. These communities, however, do not always guarantee psychological stability to the personality, since these groups themselves are characterized by variability, fluidity, and the time frame of existence. In addition, the interests of the individual and the group may not coincide, which entails the departure or exclusion of the individual from the group.

Thus, on the basis of the above-mentioned, we can conclude that the psychological aspects of identity are initially investigated in the mainstream of the classical psychoanalytic tradition, and 
subsequently become the object of analysis of socio-psychological studies. If in the works of $\mathrm{Z}$. Freud and W. James the main emphasis is placed on the personal aspects of identification, in the works of E. Fromm and his followers, attention is shifted to the social spectrum of identity problems. They investigate not only the process of identity formation, but also its types, structure, role and significance of the individual and society in the social development.

\section{ETHNIC IDENTITY: TYPES, LEVELS, STRUCTURE, FUNCTIONS}

Let us turn further in this work to considering ethnic identity and to determining the reasons for the actualization of ethnic identity in a digital society. Ethnos is one of the key social groups that, according to E. Fromm, gives rise to identity. Unlike other social groups, the ethnic community is characterized by stability, it is permeated with connections between generations, and is stable in its composition. A person as an element of an ethnos cannot leave it, he has an invariable social status and a sense of belonging. Thanks to these qualities, ethnic identity is a support and an island of stability for a person in an unstable and changeable world.

Foreign and Russian researchers usually understand ethnic identity as a special type of social identity associated with the awareness of personal belonging to an ethnic community. So T.G. Stefanenko, one of the greatest Russian specialists in the field of ethnic issues, and especially the problems of ethnic identity, believes that ethnic identity is "a psychological category that refers to the awareness of one's belonging to a particular ethnic community" [5]. Western researchers, in particular J. Phinney, note that ethnic identity is a complex multidimensional construct that includes ethnic knowledge, feelings, attitudes and behavioral reactions [6].

One of the approaches to the analysis of ethnic identity is associated with the theory of acculturation and cultural conflict. Ethnic identity comes to the fore when ethnic groups have been in contact for an extended period of time. For an ethnically homogeneous society, ethnic identity is essentially a superfluous concept. Ethnic identity, in this interpretation, should be understood as one of the aspects of acculturation, in which the main emphasis is on a person and how he interacts with his ethnic group, which is an integral part of society as a whole.

There are different types of ethnic identity: 1) mono-ethnic identity with its own ethnic group; 2) bi-ethnic identity; 3) mono-ethnic identity with a foreign ethnic group; 4) marginal ethnic identity.

The dominant type of ethnic identity, even in a digital society, continues to be monoethnic identity with its ethnic group, correlated with official belonging to a particular ethnic group. Mono-ethnic identity is carried out with varying intensity depending on specific conditions. Thus, in the case of favorable socio-historical conditions, positive ethnic identity is objectified in patriotism, feelings of dignity, pride, confidence, historical optimism [7]. As revealed in numerous studies, there is a close relationship between positive intragroup (ethnic) identity and interethnic tolerance [8]. At the same time, the hyper-identity of the individual with his ethnic group in a multiethnic society gives rise to ethnocentric stereotypes, it is accompanied by prejudice towards representatives of other ethnic communities, and leads to xenophobia and a lack of tolerance.

In the case when in a multiethnic society the social status, economic position and values of a foreign ethnic group are, for one reason or another, more significant than their own ethnic group, a change in ethnic identity occurs. In this case, a mono-ethnic identity with a foreign ethnic group arises. The result of this kind of identity is complete assimilation, that is, the acceptance of the values, language, culture and traditions of a foreign ethnic group until complete merging with it.

The internal conflict of the individual's selfidentity and his acceptance of the norms and values of certain ethnic communities are actualized at different levels and with varying degrees of intensity. Studies of ethnic identity distinguish zero, positive and negative levels of ethnic identity. The zero level is characterized by weak or no ethnic self-identity. As a strategy for the spiritual comfort and well-being of the individual, the zero level appears as a complete denial of the significance of one's own ethnic identity, both from a personal perspective and from a social perspective.

The negative level of ethnic identity is characterized by destructiveness, denial of social and group ties and relations, extremism and conflict. The positive level has a constructive potential, new social relation and strategies of activity are formed on it, ethno-national self- 
awareness is structured, new elements of the social organization of society are actualized. Thus, at a positive level of realization, ethnic identity becomes one of the factors of social stratification the principle of ethnocultural stratification.

In the structure of ethnic identity T.G. Stefanenko singles out two groups of components: 1) cognitive, including the individual's ideas about the features of his ethnic community, knowledge of its language and traditions, and his own selfidentification; 2) affective, characterizing feelings of involvement, belonging to an ethnic community, recognition of its requirements and assessment of the qualities of their community, the importance of membership in it. The cognitive component, according to T.G.Stefanenko, includes many elements: ethnic orientations, group concepts, and others. The most important of these are ethnic awareness and ethnic self-designation [9].

Recognizing the unconditional growth of ethnic identity since the second half of the twentieth century and today in a digital society, researchers mention a number of psychological reasons for this growth. The reasons for the growth of ethnic identity include: 1) the growth of global problems of our time, which gives rise to a feeling of instability and uncertainty in the present and future; 2) helplessness in the face of the threats of manmade and natural disasters; 3) acceleration of the pace of social, economic and informational development, which leads to a feeling of fatigue, inability to keep up with progress; 4) search for landmarks of sustainability and reliability in today's unstable and fluid world.

Stability and psychological security to a certain extent gives reliance on the past, history, ethnic customs and traditions of previous generations. Belonging to an ethnic community guarantees the connection between generations, recognized and time-tested value orientations and attitudes, the support of the community and the possibility of help from its side. That is why stable intergenerational social communities, primarily ethnic ones, continue to play a significant role in human life in a technogenic society.

Thus, ethnic identity for a person in the modern era performs the following functions: 1) sets the guidelines for the moral and socio-cultural order, life and personal meanings, which make it possible to form stable evaluation systems and behavioral preferences; 2) forms a basic system of values that is socially determined; 3) generates a sense of reliability and security, social community and faith in the future.

\section{PROCESSES OF ETHNIC REVIVAL IN THE CONDITIONS OF A DIGITAL SOCIETY}

The processes of ethnic revival and the search for ethnic identity at the present time in a digital society differ in forms of manifestation, goals and role in public life. The forms of ethnic selfdetermination in a digital society are diverse and multifaceted, ranging from the revival of folklore rituals, customs and traditions, and the inclusion of ethnographic elements in mass and professional culture, to the desire to recreate their national statehood or create a new one.

In crisis situations, the individual's aspiration to achieve harmony and orderliness of reality grows, while social and ethnic identities are significant factors in its achievement. The historical cataclysms of the post-Soviet era are an example of the processes of increasing ethnic selfdetermination. In the countries of the former USSR, ethnic identity is one of the most accessible forms of social self-determination and social identity. With the help of ethnic self-awareness, citizens of the post-Soviet republics seek to find a way out of the state of social confusion and confusion, to gain psychological stability and security, and to realize their involvement in a certain community. The growth of ethnic movements in the post-Soviet space is reflected in the concepts of "ethnic revolution" and "national revival" [10].

The process of the formation of ethnic and national identity in a digital society can be considered both at the level of the formation of individual consciousness, and at the level of the formation of collective ideas, values, concepts, that is, through the prism of public consciousness. If with regard to a person his ethnic status most often remains unchanged, with regard to an ethnic group it is a changeable and developing phenomenon. Thus, ethnic identity is not a static, but a dynamic formation both in relation to the individual and in relation to the ethnic community. Even for a specific individual, the process of forming ethnic identity and self-identification does not end in adolescence, since circumstances beyond his control can push a person of any age to rethink his ethnicity, which leads to the transformation of ethnic identity. Under the influence of both external circumstances and factors of a personal nature, 
ethnic self-awareness is capable of changing, acquiring a more stable character.

The term "attitude" is used to characterize the affective component of ethnic identity, reflecting the attitude of a person to his ethnic group. Attitudes, as characteristics of self-awareness, can be both positive and negative. The former include pride in belonging to their own ethnic group, satisfaction with the system of values and ideals of their ethnic community, satisfaction with their own ethnicity. Negative attitudes are based on a negative perception of one's own ethnicity, a sense of humiliation, a preference for the values and norms of other ethnic groups.

Along with factors of a personal nature and peculiarities of ethnic self-awareness, social and collective attractors, reflecting specific features of intergroup and social ties and relations in a given period of time, have a significant impact on the process of forming ethnic identity. Researchers refer to circumstances of this kind: 1) significant and crisis phenomena of socio-political life, giving rise to new relations of ethnic communities; 2) homogeneity or heterogeneity of society and ethnic environment. In addition, social factors in the formation of ethnic identity are inextricably linked with general socio-economic and socio-political processes.

These factors are subjected to detailed analysis in the works of E. Erickson, who notes that ethnic identity should be understood at three main levels: individual, personal and collective (macro level). At the individual level, ethnic identity allows not only to navigate in social realities, but also to clearly fix their place in the community, to be guided by established ethnocultural norms and values. As noted earlier, an individual with positive attitudes, based on knowledge and beliefs generally accepted by the ethnic community expresses a willingness to demonstrate adherence to these norms both within the community and outside it. As the processes of unification and standardization grow in the context of a globalizing digital society in all spheres of social life, ethnic and national factors, ethnic self-identification become the key to the preservation of socio-cultural identity and personal integrity. In the permanently emerging crisis-type conditions, it is ethnic identity that is the socio-psychological niche that allows the individual to protect himself from the negative consequences of social catastrophes.

If from the point of view of general psychology, ethnic identity is considered at the level of personality as its authentic integrity, and from the standpoint of social psychology, ethnic identity is considered as a category. The content of this category reflects the specific socio-cultural and ethno-national characteristics of the individual, assimilated by him in the process of socialization, common to the entire ethnic group.

At the macro level, ethnic identity appears as a means of achieving the unity of an ethnic group, a way of intra-ethnic mobilization. During periods of cataclysms of any nature (man-made and natural disasters, deportations, military conflicts, migration), identity is a factor contributing to the adaptation of an ethnic community to new conditions of life.

The most important role in the adaptation process is played by the institutionalized sociopolitical attitudes of the ethnic community. In the process of developing an ethnic revival in a digital society, there is the growth in the trends in the actualization of ethnic identity, the significance of the political and social-status values of members of an ethnic group increases. Ideologically and politically shaped programs and projects of activities aimed at changing the social system of society are acquiring dominant importance. Ethnic identity in the political aspect acts as a form of national ideology and political activity, the purpose of which is to change the status of an ethnic community, create and consolidate the institutional position of the group in the political and social structure of society.

Along with the revival of ethnic identity in the context of globalization and digital society, the foundations and values of the traditional local ethnic culture are changing, which entails the formation of an opposite trend - towards ethnic self-identification as a way to expand economic and political opportunities to strengthen the ideology and psychology of ethnocultural solidarity. Consequently, the processes of globalization are accompanied by a trend of ethnic and national differentiation, which is also evidence of the growth of ethnic revival. As the spatial boundaries of the digital society expand and international economic processes intensify, ethnic communities strive to achieve internal and external structural self-organization, institutionalization, and actualization of ethnic culture.

Global integration shifts include not only economic, but also information and communication interactions. The expansion of the field of interethnic relations, intercultural communication 
leads to the intensification of contacts. Interactions of this kind can be of a direct nature - these are migration and emigration, flow of refugees, tourism, student exchanges. In addition, the development of a networked society and Internet technologies leads to the improvement of the remote version of interethnic and intercultural communications. Information and communication contacts contribute to ethnic revival, make it possible to evaluate both the uniqueness and originality of one's own ethnic identity, and to compare it with others, to identify features and assess the place in the system of interethnic relations.

Based on the analysis of the processes of ethnic revival, it is possible to single out the groups of reasons for the actualization of ethnic identity in a digital society:

- a) internal personal factors that determine ethnic self-identification, algorithms of behavior, communication and relations within the ethnic community;

- b) external social factors that determine the behavioral strategies and activities of the ethnic group, based on traditional forms of culture, common history, established way of life.

From the point of view of content, functions and specificity, ethnic processes are the subject of research both in Russian and foreign science. At the same time, the positive as well as negative impacts of the ethnic revival in the digital age on various spheres of social life are highlighted, pointing out, as a result, the creative potential of ethnic revival and the possible destructive nature of its consequences.

\section{CONCLUSION}

Being one of the earliest types of socialization of an individual through an ethnic community, ethnic identity remains the leading way of organizing the social and cultural space of an individual until traditional society encounters an industrial, and after that with such type of postindustrial society as digital. In the latter, it is especially evident that the stability of individual existence is synchronized with the dynamics of the mobility of society [11]. The many times increasing differentiation and stratification of digital society offers a wide range of status positions and roles, only by adapting and mastering which the individual finds stable social positions. The social plasticity of human existence overcomes the locality of the ethnic, cultural and social space of life as the only significant social mode of reproduction of one's "I".

Ethnic identity as a significant social space of a person's existence should, as it seems, in the digital era, turn into an archaic model of his identification characteristics. But modern experience suggests otherwise. The reasons for this phenomenon lie in the fact that the social space of the life of individuals is so blurred that other identification dispositions of social subjects, with the exception of ethnic ones, are not steadily localized in it. This is what becomes the objective basis for the actualization of ethnic identity in the digital era.

\section{AUTHORS' CONTRIBUTIONS}

Vladimir Inozemtsev: Made a significant contribution to the design and development of the study design; Participated in writing and editing a draft version of the article; Approved the final version of the article for publication; Agreed to be responsible for all aspects of the study that may raise questions related to its accuracy, integrity and credibility.

Inal Sanakoev: Made a significant contribution to the collection, analysis and interpretation of data; Participated in writing a draft version of the article; Approved the final version of the article for publication; Agreed to be responsible for all aspects of the study that may raise questions related to its accuracy, integrity and credibility.

Nonna Bagramyants: Made a significant contribution to the collection, analysis and interpretation of data; Participated in editing a draft version of the article; Approved the final version of the article for publication; Agreed to be responsible for all aspects of the study that may raise questions related to its accuracy, integrity and credibility.

\section{REFERENCES}

[1] V.L. Inozemtsev. New post-industrial wave in the West. Moscow: Academy, 1999. 640 p. P. 469.

[2] E. Erikson. The Problem of Ego-identity // Psychological Issues. No. 1. New-York, 2009. P. 101-164. - P. 121.

[3] M.V. Zakovorotnaya. Human identity: social and philosophical aspects. Rostov-on-Don, 1999. $200 \mathrm{p}$. 
[4] E. Fromm. Escape from freedom. A man for himself. M $\therefore$ ACT, 2006. $571 \mathrm{p}$.

[5] T.G. Stefanenko. Ethnopsychology. Moscow: Academic project, 1999. 320 p. - P. 210.

[6] J. Phinney Ethnic identity in adolescents and adults. Review of research // Psychological Bulletin. Los Angeles: Psychological Bulletin, 1990. Vol. 108 (3). P. 499 - 514.

[7] L.I. Naumenko. Ethnic identity. Problems of transformation in the post-Soviet period // Ethnic psychology and society. M., 1997. S. 74 - 98. - P.71.

[8] N.M. Lebedeva. "The syndrome of imposed ethnicity" and ways to overcome it // Ethnic psychology and society. M., 1997. P. 104 115 .

[9] T.G. Stefanenko. Ethnic identity in a situation of social instability // Ethnic psychology and society. M., 1997. P. 97 - 104.

[10] R.G. Abdulatipov. The nature and paradoxes of the national "I". M., 1991. - P.54 - 55.

[11] M.L. Ivleva, E.M. Kurmeleva, S.V. Rudanovskaya. Man and Society in the Context of Modernity/ Issues of Philosophy, №4. Moscow: «Nauka» Publishing House, 2018. - P. 191-195. 